\title{
The efficacy and safety of feverfew (Tanacetum parthenium L.): an update of a systematic review*
}

\author{
E Ernst† and MH Pittler \\ Department of Complementary Medicine, School of Postgraduate Medicine and Health Sciences, University of \\ Exeter, 25 Victoria Park Road, Exeter EX2 4NT, UK
}

\begin{abstract}
Objective: Feverfew (Tanacetum parthenium L.) is a popular herbal remedy often advocated for the prevention of migraine. The aims of this systematic review are to update the evidence from rigorous clinical trials for or against the efficacy of feverfew for migraine prevention and to provide a safety profile of this herbal remedy.

Design: Literature searches were performed using the following databases: Medline, Embase, Biosis, CISCOM and the Cochrane Library (all from their inception to December 1999). Only randomized, placebo-controlled, double-blind trials of feverfew mono-preparations for the prevention of migraine in human subjects were included. All articles were read by two independent reviewers. Data were extracted in a pre-defined, standardized fashion. The methodological quality of the trials was evaluated by the Jadad score. For the assessment of safety issues, major reference texts were also consulted.

Results: Six trials met the inclusion/exclusion criteria. The majority favour feverfew over placebo. Yet important caveats exist. The data also suggest that feverfew is associated with only mild and transient adverse effects and few other safety concerns.

Conclusions: Feverfew is likely to be effective in the prevention of migraine. There are no major safety problems.
\end{abstract}

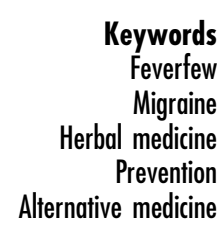

The usage of herbalism by the general US population increased by a staggering 480\% between 1990 and 1997; in 1990 the 1-year prevalence was 2.5\% while in 1997 it had risen to $12.1 \%$. Herbalism is most commonly employed for allergies, insomnia, respiratory problems and digestive problems. The out-of-pocket expenditure amounted in 1997 to $\$ 5.1$ billion $^{1}$. Faced with this remarkable revival of medical herbalism, mainstream healthcare professionals feel the need to familiarize themselves with this subject. The most pressing questions are whether herbal medicinal products (HMPs) are effective and safe.

Feverfew (Tanacetum parthenium L.) has traditionally been used as an HMP for fever, women's ailments, inflammatory conditions, psoriasis, toothache, insect bites, rheumatism, asthma and stomach-ache. During the last decades, it has been increasingly employed as a

\footnotetext{
*A previous version of a similar paper was first published in 1998 (Vogler BK, Pittler MH, Ernst E. Feverfew as a preventive treatment for migraine: a systematic review. Cephalalgia 1998; 18: 704-8).
}

remedy for migraine prophylaxis. The sesquiterpene lactone parthenolide has been suggested as its main active component. Its role in migraine prophylaxis was supported by in vitro studies suggesting inhibition of serotonin release from blood platelets (e.g. Ref. 2). A recent study, however, seems to contradict this notion ${ }^{3}$.

Regardless of these and other uncertainties, the crucial questions are, does feverfew work and is it safe? This systematic review is aimed at updating the current evidence from randomized controlled trials (RCTs) for or against the clinical efficacy of feverfew for migraine prophylaxis and at assessing the safety profile of this herbal remedy.

\section{Methods}

Systematic literature searches were performed to identify all RCTs of feverfew. Independent searches were conducted in the following electronic databases: Medline, Embase, Biosis, CISCOM and the Cochrane Library (all from their respective inception to December 1999). The 


\begin{tabular}{|c|c|c|c|c|c|c|c|c|}
\hline $\begin{array}{l}\text { First author } \\
\text { [reference] }\end{array}$ & $\begin{array}{l}\text { Jadad score } \\
\quad(\max : 5)\end{array}$ & Design & $\begin{array}{c}\text { Patients } \\
\text { entered/sample } \\
\text { size (age; years) }\end{array}$ & Medication & $\begin{array}{l}\text { Length of } \\
\text { medication } \\
\text { (months) }\end{array}$ & Main outcome measures & Result & Comments \\
\hline $\begin{array}{l}\text { Johnson et al. } \\
\text { [5] }\end{array}$ & 4 & $\begin{array}{l}\text { Two parallel } \\
\text { groups }\end{array}$ & $17 / 17$ (n.r.) & $\begin{array}{l}\text { Two capsules } \\
\text { ( } 25 \mathrm{mg} \text { ) of powdered } \\
\text { feverfew per day }\end{array}$ & 6 & $\begin{array}{l}\text { Frequency of headache } \\
\text { Incidence of nausea and } \\
\text { vomiting }\end{array}$ & $\begin{array}{l}\text { Frequency of headache } \\
\text { increased significantly } \\
(P<0.02) \text { in patients } \\
\text { receiving placebo } \\
\text { compared with baseline } \\
\text { values } \\
\text { Significant inter-group } \\
\text { differences in favour of } \\
\text { feverfew }(P<0.05) \text { for } \\
\text { the incidence of nausea, } \\
\text { vomiting }\end{array}$ & $\begin{array}{l}\text { All patients had taken } \\
\text { feverfew daily for the } \\
\text { previous } 3-4 \text { years } \\
\text { Small sample size }\end{array}$ \\
\hline $\begin{array}{l}\text { Murphy et al. } \\
\text { [6] }\end{array}$ & 4 & Crossover & 72/59 (24-72) & $\begin{array}{l}\text { One capsule } \\
\text { (mean weight: } 82 \mathrm{mg} \text { ) } \\
\text { of powdered } \\
\text { feverfew per day }\end{array}$ & 4 & $\begin{array}{l}\text { Frequency, duration } \\
\text { and severity of headache } \\
\text { Incidence of nausea and } \\
\text { vomiting }\end{array}$ & $\begin{array}{l}24 \% \text { reduction }(P<0.005) \\
\text { in attack frequency } \\
\text { Significant reduction } \\
(P<0.002) \text { of nausea and } \\
\text { vomiting } \\
\text { No change in duration } \\
\text { and severity of } \\
\text { headache }\end{array}$ & $\begin{array}{l}\text { Inhomogeneous } \\
\text { patients sample with } \\
\text { respect to former use } \\
\text { of feverfew } \\
\text { One-month placebo } \\
\text { run-in } \\
\text { No wash-out period } \\
\text { Subgroup analysis } \\
\text { in classical/common } \\
\text { migraine }\end{array}$ \\
\hline $\begin{array}{l}\text { Kuritzky et al. } \\
{[8]}\end{array}$ & * & Crossover & 20/n.r. (18-60) & $\begin{array}{l}100 \mathrm{mg} \\
\text { feverfew } \\
\text { per day }\end{array}$ & 2 & $\begin{array}{l}\text { Effect of feverfew on } \\
\text { serotonin uptake and } \\
\text { platelet activity }\end{array}$ & No effect & $\begin{array}{l}\text { Reported only as } \\
\text { abstract } \\
\text { Small sample size } \\
\text { No mention of details } \\
\text { of feverfew } \\
\text { preparations, further } \\
\text { outcome measures } \\
\text { or withdrawals }\end{array}$ \\
\hline $\begin{array}{l}\text { Weerdt et al. } \\
\text { [3] }\end{array}$ & 5 & Crossover & $50 / 44(18-64)$ & $\begin{array}{l}\text { One capsule } \\
(143 \mathrm{mg}) \text { of } \\
\text { granulated feverfew } \\
\text { per day }\end{array}$ & 4 & $\begin{array}{l}\text { Severity of headache attacks } \\
\text { Number of work days lost }\end{array}$ & $\begin{array}{l}\text { No significant effect in } \\
\text { either outcome measure }\end{array}$ & $\begin{array}{l}\text { Different drug } \\
\text { preparation } \\
\text { One month placebo } \\
\text { run-in period } \\
\text { No wash-out periods }\end{array}$ \\
\hline $\begin{array}{l}\text { Palevitch et al. } \\
\text { [7] }\end{array}$ & 3 & Crossover & $57 / 57(9-65)$ & $\begin{array}{l}\text { Two capsules } \\
(50 \mathrm{mg}) \text { of } \\
\text { powdered feverfew } \\
\text { per day }\end{array}$ & 1 & $\begin{array}{l}\text { Pain intensity } \\
\text { Severity of nausea, vomiting } \\
\text { Sensitivity to noise and light }\end{array}$ & $\begin{array}{l}\text { Significant reduction } \\
(P<0.01) \text { in each } \\
\text { outcome measure }\end{array}$ & $\begin{array}{l}\text { Both groups were } \\
\text { treated with feverfew } \\
\text { in the preliminary } \\
\text { period for } 60 \text { days } \\
\text { No wash-out period } \\
\text { No mention of the } \\
\text { patients' migraine } \\
\text { history, inclusion } \\
\text { criteria or withdrawals }\end{array}$ \\
\hline $\begin{array}{l}\text { Pfaffenrath et al. } \\
\text { [9] }\end{array}$ & * & $\begin{array}{l}\text { Four parallel } \\
\text { groups }\end{array}$ & $147 / 49$ & $\begin{array}{l}\text { A. } 2.08 \\
\text { B. } 6.25 \\
\text { C. } 18.75 \mathrm{mg} \\
\text { extract } 3 \times / \text { day } \\
\text { D. placebo }\end{array}$ & 3 & $\begin{array}{l}\text { Frequency of migraine } \\
\text { attacks }\end{array}$ & Significant reduction & $\begin{array}{l}\text { Dose-response } \\
\text { relationship observed }\end{array}$ \\
\hline
\end{tabular}


search terms were feverfew, Tanacetum parthenium, Chrysanthemum parthenium, Mutterkraut (the German common name), headache and migraine. A manual search was performed using the bibliographies of articles located through the computer search and through scanning our own files. In addition, leading manufacturers of feverfew preparations were contacted and asked to contribute published and unpublished material.

Only double-blind, placebo-controlled RCTs of feverfew for migraine prophylaxis were included. Studies were excluded if not performed on feverfew mono-preparations. There were no restrictions regarding publication language. Data were extracted independently by two reviewers following a standardized, predefined procedure. Methodological quality was assessed using the Jadad score ${ }^{4}$. A metaanalysis was considered but proved to be infeasible due to the lack of a common outcome measure across the studies.

\section{Results}

\section{Efficacy}

Six clinical studies met the above inclusion/exclusion criteria (Table 1). All trials scored at least 2 of 5 points on the Jadad score. Four studies reporting positive results favouring feverfew scored $3-4$ points on the quality scale ${ }^{5-7,9}$. One of the two negative trials scored 5 points $^{3}$ (Table 1 ).

Johnson et al. $^{5}$ conducted a trial including 17 patients who had consumed raw feverfew leaves every day for the previous 3-4 years. Patients were randomized to receive either two capsules of freeze-dried feverfew leaves daily $(50 \mathrm{mg}$ ) or identical placebo for 24 weeks. During the trial period all patients graded severity and frequency of headache, visual disturbance, incidence of nausea and vomiting on diary cards. A significant increase of mean attack frequency per month was observed in the placebo group compared with baseline measurements $(P<0.02)$, while this parameter remained constant in patients receiving feverfew. Five of eight patients from the feverfew group reported good to excellent effectiveness, while this was reported by only one patient in the placebo group.

Murphy et $a l .^{6}$ randomized 72 patients to receive either one capsule of feverfew or placebo for 4 months after a 1 month placebo run-in period. Patients were subsequently crossed over into the other group for the second 4-month period. Feverfew treatment was associated with a $24 \%$ reduction $(P<0.005)$ in attack frequency and a significant decrease $(P<0.02)$ in migraine-associated nausea and vomiting compared with placebo. In patients with common migraine, feverfew reduced the number of attacks by $21 \%$ $(P=0.06)$ while it was reduced by $32 \%(P<0.05)$ in patients with classical migraine.

Kuritzky et $a l^{8}$ assessed the effect of feverfew on serotonin uptake and platelet activity in 20 migraine patients. Each patient received $100 \mathrm{mg}$ of feverfew or placebo daily for 2 months. No effect on serotonin uptake and platelet activity was found. Without providing details of clinical data, the authors concluded: ' $100 \mathrm{mg}$ of feverfew a day was found to be ineffective in the prophylaxis of migraine'.

Weerdt et $a l^{3}$ administered either one capsule of an alcoholic feverfew extract or placebo to 50 patients in a crossover RCT. A 1-month placebo run-in phase was followed by two treatment periods of 2 months each. The frequency of headache attacks and the number of work days lost were reported in a daily calendar. The results showed no statistically significant beneficial effect of feverfew compared with placebo.

A crossover trial conducted by Palevitch et $\mathrm{al}^{7}{ }^{7}$ included 57 migraine patients. During the preliminary phase of this study each patient was treated with $100 \mathrm{mg}$ feverfew daily for 2 months. Thereafter, one group received placebo for an additional 30 days while the other group continued taking feverfew. In the third phase, the treatment group was crossed over to the placebo arm and vice versa. Pain intensity and severity of the accompanying symptoms such as nausea, vomiting and sensitivity to noise and light were reported. The results of the preliminary phase showed a significant decrease in pain intensity after the treatment with feverfew compared with baseline $(P<0.001)$. In the crossover phase, a significant reduction of pain intensity was reported in the treatment group compared with the placebo group $(P<0.01)$. There was also a significant reduction in the severity of nausea and vomiting in favour of feverfew.

Pfaffenrath et $a l^{9}$. conducted a double-blind, placebocontrolled, multicentre RCT which, so far, has only been published as an abstract (for this reason no Jadad score was attributed to this study). Three dosage regimens $(2.08 \mathrm{mg}$ vs. $6.25 \mathrm{mg}$ vs. $18.75 \mathrm{mg}$, each 3 times per day administered for 12 weeks) of a novel $\mathrm{CO}_{2}$ feverfew extract were compared with placebo. One hundred and forty seven patients with migraine (according to International Headache Society criteria) were enrolled. The primary endpoint had been pre-defined as the total number of migraine attacks during the last 28 days of treatment compared with the 4 -week baseline period. The results showed significant effects compared with placebo and a dose-response relationship. The optimal effectiveness was noted with $3 \times$ $6.25 \mathrm{mg}$ extract per day. The authors concluded that this extract was 'particularly effective in migraine prophylaxis in patients with at least 4 attacks during 28 days prior to onset of prophylaxis'.

\section{Safety}

Adverse effects, as reported in the above trials, are summarized in Table 2. Feverfew was generally well tolerated and adverse effects were usually mild and reversible. Two studies ${ }^{5,6}$ reported a higher and one trial ${ }^{9}$ a similar incidence of adverse effects in the placebo group compared with the feverfew group. In total, three withdrawals were necessitated by adverse effects in the feverfew groups compared with five in the placebo groups. 
Table 2 Adverse effects of feverfew as reported in RCTs

\begin{tabular}{|c|c|c|c|}
\hline $\begin{array}{l}\text { First author } \\
\text { [reference] }\end{array}$ & Type of adverse effect & $\begin{array}{l}\text { Withdrawals } \\
\text { (feverfew/placebo) }\end{array}$ & Comments \\
\hline Johnson et al. [5] & $\begin{array}{l}\text { Nervousness, tension headache, } \\
\text { insomnia, stiffness in joints, tiredness, } \\
\text { nausea, heavier or lighter periods, } \\
\text { palpitations, colicky abdominal pain }\end{array}$ & $(0 / 2)$ & $\begin{array}{l}\text { All patients taking placebo reported one } \\
\text { event with adverse effects, whereas four } \\
\text { patients taking feverfew reported none }\end{array}$ \\
\hline Murphy et al. [6] & $\begin{array}{l}\text { Mouth ulceration, indigestion, heartburn, } \\
\text { dizziness, skin rash, diarrhoea, } \\
\text { abdominal bloating, sore mouth, weight } \\
\text { gain, flatulence, nausea, constipation }\end{array}$ & $(2 / 3)$ & $\begin{array}{l}\text { Mouth ulceration was more common } \\
\text { with placebo }\end{array}$ \\
\hline Kuritzky et al. [8] & n.r. & n.r. & Only reported in abstract form \\
\hline Weerdt et al. [3] & Diarrhoea & $(1 / 0)$ & None \\
\hline Palevitch et al. [7] & n.r. & n.r. & None \\
\hline Pfaffenrath et al. [9] & Minor Gl symptoms & n.r. & Only reported in abstract form \\
\hline
\end{tabular}

n.r., not reported.

A 'post-feverfew syndrome' has been described after allocating patients who previously were taking feverfew to placebo treatment ${ }^{5}$. Feverfew did not appear to affect blood pressure, heart rate, body weight, or the results of haematological and biochemical safety parameters.

Sources other than the above-mentioned RCTs need to be consulted to generate reliable information on the safety of feverfew. Information from several recent reference texts ${ }^{10-15}$ has been extracted and is summarized in Table 3. These cumulative data suggest that feverfew is not entirely free of risks but that adverse effects are usually transient and mild.

\section{Discussion}

In view of the popularity of feverfew, the paucity of the existing RCTs on the subject is disappointing. Most of the studies that exist are not fully satisfactory in terms of methodological quality. Collectively, however, the data do imply that feverfew is effective in preventing migraine attacks.

While the study with the highest Jadad score ${ }^{3}$ showed no beneficial effects, four of the six trials ${ }^{5-7,9}$ favoured feverfew. Amongst the four trials with an acceptable sample size ${ }^{16}$, three studies ${ }^{6,7,9}$ reported feverfew to be superior to placebo while one ${ }^{3}$ did not. The frequency of migraine was positively affected by feverfew in three trials $^{5,6,9}$. Feverfew reduced the severity of migraine in one trial $^{7}$ while two studies ${ }^{3,6}$ reported no such effect. The incidence of nausea and vomiting was positively affected in two ${ }^{5,6}$ of four trials, while severity was reduced in one study $^{7}$.

It is often assumed that parthenolide represents the active principal of feverfew. This hypothesis is supported by in vitro experiments demonstrating that feverfew has inhibitory effects on platelet aggregation as well as release of serotonin from blood platelets and leucocytes ${ }^{8,17}$. Feverfew also inhibits prostaglandin biosynthesis ${ }^{18}$ by interfering with phospholipase $\mathrm{A}^{19}$. However, a definitive

Table 3 Risks of feverfew - information from major recent reference texts

\begin{tabular}{|c|c|c|}
\hline Adverse effects & Cautions and contraindications & Drug interactions \\
\hline $\begin{array}{l}\text { Abdominal pain } \\
\text { Bitter taste* } \\
\text { Contact dermatitis } \\
\text { Diarrhoea } \\
\text { Dry, sore tongue* } \\
\text { Fatigue† } \\
\text { Flatulence } \\
\text { Gl symptoms } \\
\text { Indigestion } \\
\text { Inflammation of lips or tongue* } \\
\text { Joint pain } † \\
\text { Loss of taste* } \\
\text { Mouth ulceration* } \\
\text { Nausea/vomiting } \\
\text { Nervousness } \\
\text { Swollen lips* } \\
\text { Tension† }\end{array}$ & $\begin{array}{l}\text { Children under } 12 \text { years } \\
\text { Not longer than for } 4 \text { months } \\
\text { Known hypersensitivity } \\
\text { Pregnancy/lactation } \\
\text { Feverfew is not effective in treating acute } \\
\text { migraine attacks }\end{array}$ & $\begin{array}{l}\text { Enhanced effects of platelet inhibitors } \\
\text { Effect reduced when taken with NSAIDs }\end{array}$ \\
\hline
\end{tabular}

* Not when taken in capsules.

† During feverfew withdrawal. 
link between the aetiology of migraine and parthenolide or any other feverfew constituent has not been established beyond reasonable doubt. One trial using an extract of feverfew with a standardized concentration of parthenolide did not show any beneficial effect ${ }^{3}$. This lack of effectiveness may be due to the absence of essential therapeutic components of the granulated feverfew leaves ${ }^{3}$. A divorce from the serotonin inhibition theory might lead to more attention being given to the other components of the feverfew leaf ${ }^{20}$. This is supported by a study ${ }^{21}$ that states a secondary role of serotonin in the aetiology of migraine. The results of the Dutch study ${ }^{3}$ suggested that the essential oil constituent of feverfew, chrysanthemyl acetate, may be important. This component inhibits prostaglandin synthetase in vitro and seems to possess analgesic properties ${ }^{18}$. Other investigators also agree that parthenolide is not the only pharmacological active constituent in feverfew ${ }^{22,23}$. A link between the relatively high concentration of melatonin in different feverfew varieties ${ }^{24}$ and a decrease in melatonin excretion during migraine attacks has been suggested ${ }^{25}$. An alternative explanation for negative trial results is offered by the fact that some commercial preparations are underdosed, possibly due to the instability of the active constituents in these extracts ${ }^{26}$.

How safe is feverfew? Chronic prophylactic use of feverfew did not affect the frequency of chromosomal aberration in lymphocytes or urine mutagenicity ${ }^{27}$. Anecdotal reports relate to contact dermatitis (e.g. Refs. 28 and 29). In the RCTs reviewed here, adverse effects were generally mild and reversible. Mouth ulceration and gastrointestinal symptoms were the most frequent adverse effect, also experienced by long-term feverfew users ${ }^{30}$. Obviously such problems can be avoided through adequate galenic design of the HMP. A 'post feverfew syndrome' including a rebound of migraine symptoms, anxiety, insomnia, and muscle and joint stiffness was reported by long-term consumers after discontinuation of feverfew ${ }^{5}$.

How useful are systematic reviews? SRs minimize selection and random biases, yet they are not totally biasfree. The tendency for negative trials to remain unpublished is well $\mathrm{known}^{31}$. Conversely, in journals of complementary or alternative medicine positive studies may be over-represented ${ }^{32,33}$. Such publication biases may distort the overall result of SRs. Other problems of SRs of HMPs pertain to the heterogeneity of extracts and the often low methodological quality of the original trials. Nevertheless, at my department we firmly believe that SRs of HMPs do offer a valuable step forward and have therefore conducted numerous SRs similar to the one presented here. This work has been recently summarized elsewhere ${ }^{34}$.

In conclusion, the results of RCTs favour feverfew over placebo as a preventive treatment for migraine. However, several caveats prevent firm conclusions as to the efficacy of feverfew. Major safety problems do not seem to exist.

\section{References}

1 Eisenberg DM, David RB, Ettner SL, et al. Trends in alternative medicine use in the United States, 1990-1997. JAMA 1998; 280: 1569-75.

2 Heptinstall S, White A, Williamson L, Mitchel JRA. Extracts of feverfew inhibit granule secretion in blood platelets and polymorphonuclear leucocytes. Lancet 1985; i: 1071-4.

3 De Weerdt CJ, Bootsma HPR, Hendriks H. Herbal medicines in migraine prevention: randomized double-blind placebo-controlled crossover trial of a feverfew preparation. Phytomedicine 1996; 3: 225-30.

4 Jadad AR, Moore RA, Carrol D, Jenkinson C, Reynolds DJM, Gavaghan DJ, et al. Assessing the quality of reports of randomized clinical trials: is blinding necessary? Controlled Clin. Trials 1996; 17: 1-12.

5 Johnson ES, Kadam NP, Hylands DM, Hylands PJ. Efficacy of feverfew as prophylactic treatment of migraine. BMJ 1985; 291: $569-73$.

6 Murphy JJ, Heptinstall S, Mitchell JRA. Randomized doubleblind placebo-controlled trial of feverfew in migraine prevention. Lancet 1988; i: 189-92.

7 Palevitch D, Earon G, Carasso R. Feverfew (Tanacetum parthenium) as a prophylactic treatment for migraine: A double-blind placebo-controlled study. Phytother. Res. 1997; 11: $508-11$

8 Kuritzky A, Elhacham Y, Yerushalmi Z, Hering R. Feverfew in the treatment of migraine: its effect on serotonin uptake and platelet activity. Neurology 1994; 44 (Suppl. 2): 293P.

9 Pfaffenrath V, Fischer M, Friede M, Heinneicke V, Zepelin HH. Clinical dose-response study for the investigation of efficacy and tolerability of Tanacetum parthenium in migraine prophylaxis. Proceedings of Deutscher Schmerzkongress, 1999.

10 Fetow CW, Avila JR. Complementary and Alternative Medicines. Springhouse: Philadelphia, 1999.

11 Boon H, Smith M. The Botanical Pharmacy. Kingston, Canada: Quarry Press, 1999.

12 Ernst E. Possible interactions between synthetic and herbal medicinal products. Part 1: a systematic review of the indirect evidence. Perfusion 2000; 13: 4-15.

13 Lininger SW. A-Z Guide to Drug-Herb-Vitamin Interactions. Rocklin, CA: Prima Publishing, 1999.

14 Newall CA, Anderson LA, Phillipson JD. Herbal Medicines. London: The Pharmaceutical Press, 1996.

15 Brinker R. Herb Contraindications and Drug Interactions. Sandy, OR: Eclectic Medical Publications, 1998.

16 Tfelt-Hansen P, Nielsen SL. Patient numbers needed in prophylactic migraine trials. Neuroepidemiology 1987; 6: 214-19.

17 Heptinstall S, Groenewegen WA, Spangenberg P, Loesche W. Extracts of feverfew may inhibit platelet behaviour via neutralization of sulphydryl groups. J. Pharm. Pharmacol. 1987; 39: 459-65.

18 Pugh WJ, Sambo K. Prostaglandin synthetase inhibitors in feverfew. J. Pharm. Pharmacol. 1988; 40: 743-5.

19 Makheja AN, Bailey JM. A platelet phospholipase inhibitor from the medicinal herb feverfew (Tanacetum parthenium). Prostaglandins Leukotrienes Med. 1982; 8: 653-60.

20 Awang DVC. Prescribing therapeutic feverfew (Tanacetum parthenium (L.) Schultz Bip., syn Chrysanthemum parthenium (L.) Bernh.). Integrative Med. 1998; 1: 11-13.

21 Goadsby PJ. How do the currently used prophylactic agents work in migraine? Cephalalgia 1997; 17: 85-92.

22 Brown AMG, Edwards CM, Davey MR, Power B, Lowe KC. Pharmacological activity of feverfew (Tanacetum parthenium (L.) Schultz-Bip.): Assessment by inhibition of human polymorphonuclear leucocyte chemiluminescence in-vitro. $J$. Pharm. Pharmacol. 1997; 49: 558-61.

23 Hendriks H, Bos R, Woerdenbag HJ. The essential oil of 
Tanacetum parthenium (L.) Schultz-Bip. Flavour Fragrance J. 1996; 11: 367-71.

24 Murch SJ, Simmons CB, Saxena PK. Melatonin in feverfew and other medicinal plants. Lancet 1997; 350: 1598-9.

25 Brun J, Claustrat B, Saddier P, Chazor G. Nocturnal melatonin excretion is decreased in patients with migraine without aura attacks associated with menses. Cephalalgia 1995; 15: $136-9$.

26 Willigmann J, Freudenstein J. Production of a stable feverfew (Tanacetum parthenium) extract as an active substance for a pharmaceutical product. Scharper Brümmer 1999 (internal document)

27 Anderson D, Jenkinson PC, Dewdney RS, Blowers SD, Johnson ES, Kadam NP. Chromosomal aberrations and sister chromatid exchanges in lymphocytes and urine mutagenicity of migraine patients: a comparison of chronic feverfew users and matched non-users. Hum. Toxicol. 1988; 7: 145-52.

28 Burry JN. Compositae dermatitis in South Australia: Contact dermatitis from Chrysanthemum parthenium. Contact Dermatitis 1980; 6: 445.

29 Hausen BM, Osmundsen PE. Contact allergy to parthenolide in Tanacetum parthenium (L.) Schulz-Bip. (Feverfew, Asteraceae) and cross-reactions to related sesquiterpene lactone containing compositae species. Acta Derm. Venereol. 1983; 63 308-14.

30 Johnson ES. Patients who chew chrysanthemum leaves. MIMS Mag. 1983; 15 May: 32-5

31 Easterbrook PJ, Berlin JA, Gopalan R, Matthews DR. Publication bias in clinical research. Lancet 1991; 337: 867-72.

32 Ernst E, Pittler MH. Alternative therapy bias [letter]. Nature 1997; 385: 480.

33 Pittler MH, Abbot NC, Harkness EF, Ernst E. Location bias in controlled clinical trials of complementary medicine. J. Clin. Epidemiol. 2000; 53: 485-9.

34 Ernst E, ed. Herbal Medicine. A Concise Overview for Professionals. Oxford: Butterworth-Heinemann, 2000. 